ECOLOGICA, Vol. 28, No 101 (2021), 65-71

https://doi.org/10.18485/ecologica.2021.28.101.11

Originalni naučni rad

UDC:502.174:33

\title{
Cirkularna ekonomija i izazovi globalnog tržišta
}

\section{The circular economy and global market challenges}

\author{
Srđan Bogetić1, Dejan Đorđević2, Dragan Ćočkalo ${ }^{3}$ \\ Ljiljana Đorđević ${ }^{4}$, Mihalj Bakator ${ }^{5}$ \\ ${ }^{1}$ Beogradska poslovna i umetnička akademija strukovnih studija Beograd, Republika Srbija \\ ${ }^{1}$ Belgrade Business and Art Academy of Vocational Studies Belgrade, Republic of Serbia \\ 2,3,5Univerzitet u Novom Sadu, Tehnički fakultet "Mihajlo Pupin", Zrenjanin, Republika Srbija \\ 2,3,5University of Novi Sad, Technical Faculty "Mihajlo Pupin", Zrenjanin, Republic of Serbia \\ ${ }^{4}$ Agencija za zaštitu životne sredine, Republika Srbija \\ ${ }^{4}$ Environmental Protection Agency, Republic of Serbia
}

Rad primljen: 15.12.2020, Rad prihvaćen: 18.02.2021.

Sažetak: U savremenom poslovanju koje karakteriše velike ekonomske, tehnološke i ekološke promene, značajnu ulogu ima cirkularna ekonomija (CE). Koncept cirkularne ekonomije kao paradigma održivog razvoja vodi računa o pitanju upravljanja otpadom, njegovom daljom reciklažom i stvarnjem nove vrednosti koje omnogućava preduzeću dalji nastavak životnog ciklusa proizvoda. Pod akterima u cirkularnoj ekonomiji podrazumevamo preduzeća, potrošače, građane i predstavnike nevladinih organizacija. Takođe, države se smatraju kritičnom podrškom primene CE. Međutim, i pored razumevanja prednosti cirkularne ekonomije za savremeno poslovanje, na globalnom nivou broj država i preduzeća koja prihvataju ovaj koncept je nedovoljan. Razlozi se mogu naći u visokoj stopi vađenja rude, ogromnim zalihama i nedovoljnom nivou upotrebljivosti i recikliranja. Standardizacija i preduzetništvo predstavljaju jedne od oblasti koje preduzeća treba da razviaju ukoliko žele efikasniju primenu CE. Preduzetničko ponašanje omogućava razvoj inovativnosti u preduzeću, što doprinosi boljoj reciklaži i kreiranju novog proizvoda.

Ključne reči: cirkularna ekonomija, održivi razvoj, upravljanje otpadom, preduzetništvo, standardizacija.

\begin{abstract}
In modern business operations, which are characterized by major economic, technological and environmental changes, a significant role is played by the circular economy (CE). The concept of circular economy as a paradigm of sustainable development takes into account the problems of waste management, its further recycling and the creation of new value that enables the company to continue the life cycle of the product. By actors in the circular economy, we presume companies, consumers, citizens and representatives of non-governmental organizations. Moreover, states are considered to be of critical support for the implementation of CE. However, despite being aware of the benefits of the circular economy for modern business, globally speaking, the number of countries and companies that accept this concept is scarce. The reasons can be found in the high rate of ore extraction, huge inventories and low level of usability and recycling. Standardization and entrepreneurship are some of the areas that companies need to develop if they want to implement CE more efficiently. An entrepreneurial attitude leads to the development of innovation in the company, which contributes to stronger recycling and the creation of a new product.
\end{abstract}

Keywords: circular economy, sustainable development, waste management, entrepreneurship, standardization.

\footnotetext{
${ }^{1}$ orcid.org/0000-0003-1855-0767, e-mail: sbogetic@yahoo.com

2orcid.org/0000-0001-9453-9207, e-mail: dejan.djordjevic@tfzr.rs

3orcid.org/0000-0003-2085-5420,e-mail:dragan.cockalo@uns.ac.rs

${ }^{4}$ orcid.org/0000-0001-8318-7189, e-mail: ljiljana.djordjevic@sepa.gov.rs

5orcid.org/0000-0001-8540-2460, e-mail: mihalj.bakator@uns.ac.rs
} 


\section{UVOD / INTRODUCTION}

Realizacije procesa održivog razvoja imaće značajnu ulogu u svetskoj ekonomiji u narednim decenijama. U tom smislu posmatrano, proces upravljanja otpadnim materijalima postaje važan činilac ekonomskog razvoja. Preovlađujući način proizvodnje podrazumeva da se proces proizvodnje zasniva na eksploataciji pririodnih resursa, proizvod izlazi na tržište, a nakon upotrebe, proizvod se odlaže na deponiju. Ovaj model ekonomije je poznat kao linearni model poslovanja. Dugogodišnja primena linearnog modela dovela je do prekomerne eksploatacije prirodnih resursa i nagomilavanja otpada, što je rezultovalo fizičkim ograničenjima ovog modela. Danas se sve više govori o modelu poslovanja koji se fokusira na ponovnoj upotrebi resursa i procesima reciklaže. Taj model poslovanja se označava kao cirkularna ekonomija (CE). Model cirkularne ekonomije se smatra ključnim pristupom u procesu tranzicije ka modelu održive ekonomije i način za postizanje određenih ciljeva održivog razvoja UN-a (Sustainable Development Goals - SDGs).

Cirkularna ekonomija kao tema u poslednjoj deceniji predstavlja važan fokus poslovnih strategija, politika vladinih institucija i akademskih istraživanja (llić-Kosanović et al., 2019). Prema nekim shvatanjima (OEBS), cirkularna ekonomija podrazumeva kruženje materijala i njegovu ponovnu upotrebu, čime se istovremeno koristi drastično manje energije i vode, u nekim slučajevima i preko $90 \%$. Evropska komisija (Europska komisija, 2015), definiše cirkularnu ekonomiju kao ekonomiju u kojoj se "vrednost proizvoda, materijala i resursa zadržava u privredi što je duže moguće, a otpada stvara na minimumu". Kao rezultat ovih aktivnosti Evropska unija može da uspostavi održivu i konkurentnu ekonomiju u kojoj je niska emisija ugljen diokisida i u kojoj se resursi efikasno koriste. Pojedini autori (Maldonado-Guzmán et al., 2020), cirkularnu ekonomiju posmatraju kao novu paradigmu održivosti.

Cirkularna ekonomija je ekonomski model koji pokušava da izvuče najveću moguću vrednost iz materijala i energije koji se koriste u proizvodima kako bi se izbegla nepotrebna i prekomerna potrošnja sirovina i energije. Iz perspektive cirkularne ekonomije, ono što se generalno smatra otpadom, umesto toga se smatra potencijalnim resursom koji se može koristiti kao sirovina, komponenta ili izvor energije, bilo $u$ istom procesu ili $u$ drugom lancu snabdevanja. Glavni cilj je da materijali, komponente i otpad nastave da cirkulišu, čime se maksimizira vrednost resursa (Lopes de Sousa Jabbour, 2019).

Orijentacija nacionalne ekonomije ka cirkularnoj ekonomiji omogućava, da se sa jedne strane vred- nost proizvoda, materijala i resursa zadrži u privredi što je duže moguće, dok je sa druge strane stvaranje otpada na minimumu. Kao posledica ovakve orijentacije nacionalne ekonomije omogućiće razvijanje održive i konkurentne ekonomije u kojoj se svi resursi efikasno koriste.

Cirkularna ekonomija će građanima doneti visokokvalitetne, funkcionalne i sigurne proizvode koji su efikasni i pristupačni, traju duže i mogu se ponovo koristiti, popraviti i reciklirati uz visok kvalitet. Niz novih održivih usluga, modeli „proizvoda kao usluge“ i digitalna rešenja povećaće kvalitet života građana, otvoriće inovativna radna mesta i modernizovati znanje i veštine (Europska komisija, 2020).

Evropska unija (EU) je od 2015. godine usvojila strateški dokument iz oblasti održivog razvoja "Akcioni plan cirkularne ekonomije" i na taj način započela sa aktivnijim promovisanjem ovog modela poslovanja. Kao rezultat Akcionog plana cirkularne ekonomije, nastali su zakonodavna dokumenta koja definišu ovu oblast kao što su: Evropska platforma zainteresovanih strana za cirkularnu ekonomiju i Urbanistička agenda za partnerstvo EU o cirkularnoj ekonomiji. U cilju što efikasnijeg prilagođavanja novom modelu poslovanja, Evropska komisija ubrzano radi na kreiranju akcionog plana cirkularne ekonomije koja će predstavljati program u kojoj su ključni akteri: preduzeća, potrošači, građani i predstavnici nevladinih organizacija, što za cilj ima kreiranje čiste i konkurentne ekonimije EU.

Međutim, i pored značanih prednosti koje donosi cirkularna ekonomija, ona još uvek nije dovoljno zastupljena na globalnom nivou. Podaci o zastupljenosti cirkularne ekonomije za 2020. godinu (8,6\%) pokazali su da postoji pad u odnosu na prethodnu godinu $(9,1 \%)$.

\section{ANALIZA OSNOVNIH ASPEKATA KONCEPTA CIRKULARNE EKONOMIJE / ANALYSIS OF BASIC ASPECTS OF THE CIRCULAR ECONOMY CONCEPT}

Ekonomski razvoj, zaštita životne sredine i razvoj društvene zajednice su međusobno povezani. Savremena poslovna organizacija koja želi da ostvari dugoročni poslovnih uspeh, mora svoj poslovni razvoj da uskladi za zahtevima za zaštitu i unapređenje životne sredine, po osnovu proizvodnje ekološki prihvatljivih proizvoda, integralnog upravljanja otpadom i zaštite prirodnih resursa (zemlja, voda, vazduh, itd). Takođe, poslovna organizacija mora da utiče i na razvoj društvene zajednice, po osnovu unapređenja kvaliteta ljudskih resursa (Bakator et al., 2019). 
$\mathrm{Na}$ globalnom planu se već duži niz godina definišu smernice održivog razvoja, koji treba da uspostavi ravnotežu između ciljeva ekonomskog razvoja i socijalnog razvoja, uvažavajući potrebu za unapređivanjem i zaštitom životne sredine. Savremeno društvo upućuje preduzeću sve više zahteva u pravcu definisanja njegove društvene odgovornosti - preduzeća moraju da postanu odgovorna za svoje ponašanje u društvu i životnom okruženju, dugoročno posmatrano. Jedan od osnovnih zaključaka Agende 21, koja pretstavlja uputstvo za primenu i sprovođenje koncepta održivog razvoja u svim sektorima razvoja i korišćenja životne sredine u 21. veku, jeste da je reciklaža otpada nesumnjivo najbolji i najracionalniji način upravljanja otpadnim materijalima.

Sveukupni negativni trend može se objasniti sa tri povezana, osnovna uzroka: visoka stopa ekstrakcije (vađenja ruda), kontinuirano gomilanje zaliha, nizak nivo upotrebljivosti i recikliranja (PACE, 2020). Zemlje su kritični pomagači cirkularne ekonomije. To nije zbog onoga što su postigli u prošlosti, već zbog onoga što bi mogli da pruže $u$ budućnosti. Početna grupa zemalja angažovala se na cirkularnom programu, počev od pojedinačnih nacionalnih država u Evropi, do gigantske kineske ekonomije. Ipak, poslednjih godina svedoci smo stalnog toka novih igrača koji usvajaju politike i mape puta cirkularne ekonomije. Na primer, 2019. godine Kolumbija je lansirala svoju Nacionalnu strategiju cirkularne ekonomije, prvu takvu u Latinskoj Americi (PACE, 2020).

Cirkularna ekonomija nudi novi poslovni model koji podrazumeva relaciju proizvod-otpad-proizvod. $\mathrm{Da}$ bi se stvorili uslovi za nesmetani ekonomski rast uz smanjenje količine otpada i smanjenja ekstrakcije prirodnih resursa, neophodno je da se u što većoj meri realizuje proces ponovne upotrebe materijala koji su završili svoj životni ciklus. Umesto razmišljanja o otpadu, potrebno je da se fokusira ponovna upotreba materijala u procesu reciklaže. Proizvodi treba da budu tako osmišljeni da mogu da se ponovo upotrebe, da se rastave na sastavne delove i recikliraju. Takođe, u procesu proizvodnje potrebno je da se koristi što više energije iz obnovljivih izvora. Prednosti od implementacije koncepta cirkularne ekonomije su značajne, a posebno se izdvajaju: zaštita prirodnih resursa i životne sredine, štednje energije, povećanje zaposlenosti, kao i unapređenje inovativnosti i konkurentnosti ekonomije.

Prema mišljenju Ellen Macarthur fondacije principi cirkularne ekonomije su (Ellen Macarthur foundation, 2019): dizajnirati otpad i zagađenje, držanje proizvoda i materijala u upotrebi i regenerisanje prirodnih sistema.

Prelazak na cirkularnu ekonomiju zahteva radikalnu promenu u načinu na koji proizvodimo i trošimo. U cirkularnoj ekonomiji, proizvodi su dizajnirani za izdržljivost, nadogradnju, popravljivost i ponovnu upotrebu, s ciljem ponovne upotrebe materijala od kojih su napravljeni nakon što završe svoj životni vek. $U$ fazi upotrebe, proizvodima se upravlja $s$ ciljem da se maksimalizuje njihov upotrebni kapacitet i produži životni vek, održavajući na taj način vrednost što je duže moguće. To su omogućile kompanije koje razvijaju nove poslovne modele generišući tokove prihoda od usluga, a ne od proizvoda, istovremeno efikasnije koristeći resurse $\mathrm{i} / \mathrm{ili}$ dajući novu vrednost proizvodima i materijalima nakon isteka životnog veka. Potrošači proizvode efikasno koriste i odbacuju na takav način da se mogu ponovo upotrebiti ili, ako je to tehnički ili ekonomski neizvodljivo, operateri reciklaže pretvaraju in u sekundarne materijale koji mogu ući u novi ciklus proizvodnje i potrošnje (European Commission Directorate-General for Research and Innovation, 2019).

Odgovorna potrošnja i proizvodnja predstavljaju jedan od ciljeva održivog razvoja (Eurostat, 2018). Indikatori koji se odnose na merenje ovog cilja održivog razvoja su smanjivanje zagađenja životne sredine u odnosu na uticaj ekonomskog razvoja, održiva potrošnja energije i kreiranje i upravljanje otpadom.

Vađenje ruda podstaklo je prosperitetan rast od industrijske revolucije. Zapravo, tokom poslednjih pet decenija, globalna upotreba rude se više nego utrostručila - povećavši se za faktor 3,5 , sa 26,7 milijardi tona 1970. godine, na 92,0 milijardi tona 2017. godine. Međunarodni panel resursa (International Resource Panel - IRP) predviđa da će do 2050. godine, upotreba materijala iznositi između 170 i 184 milijarde tona. Deo ovih milijarda tona izvađenih sastojaka čine inherentno necirkularni i neregenerativni materijali - na primer, naftni derivati poput benzina, sagorenih u motorima sa unutrašnjim sagorevanjem (PACE, 2020).

Primenom različitih postupaka reciklaže otpadnih materijala smanjuje se trošenje prirodnih resursa vraćanjem korisnih materija i postiže se ušteda energije. Reciklažom se dvostruko deluje na društvo:

- efikasno se rešava deo ekoloških problema, nastalih po osnovu zagađivanja životne sredine otpadnim materijalima $\mathrm{i}$ 
- $\quad$ stvaraju se uslovi za realizaciju proizvodnje po nižim troškovima, uz smanjivanje obima korišćenja primarnih sirovina.

Da bi se ostvarili maksimalni efekte procesa reciklaže u odnosu na pomenute aspekte (ekološki i ekonomski), potrebno je da bude institucionalno definisana, što podrazumeva preciznu programsku orijentaciju i zakonsku regulativu, kao i moderan pristup upravljanju otpadom.

Prema nekim shvatanjima (Đorđević i Bjelović, 2008), strategija odnosa prema otpadu, označena je kao "Program 3R": Redukovanje otpada - minimizacija, ponovno iskorišćavanje potencijalnog otpada - Reiskorišćavanje i Reciklaža - prerada sirovinski upotrebljivih materijala iz otpada. Program 3R pretpostavlja zakonske, organizacione i edukacione okvire, kao i konkretne mehanizme i instrumente upravljanja otpadom.

$U$ oblasti industrijske proizvodnje posebna pažnja se posvećuje ekološkoj efikasnosti (u odnosu na zagađivanje) - postoji značajan uticaj ekoloških poreza i dobrovoljnih sporazuma orijentisanih $u$ pravcu smanjivanja stvaranja otpada. Politika EU u domenu upravljanja otpadom je usmerena dokumentom koji se zove Strategija upravljanja otpadom, i čiji je osnovni cilj uspostavljanje politike upravljanja otpadom na nivou EU. Strategija se zasniva na hijerarhiji principa, dajući prioritet prevenciji nastajanja otpada, zatim ponovnoj upotrebi i reciklaži materijala i regeneraciji energije i konačnom odlaganju otpada. Prema izveštaju EU, stopa upotrebe cirkularnih materijala u EU iznosi $11, \$ \%$, a stopa reciklaže iznosi $55 \%$ od ukupno kreiranog otpada (Eurostat, 2018).

Situacija u domaćoj privredi po pitanju implementacije integralnog koncepta upravljanja otpadom u cilju izgrađivanja cirkularne ekonomije nije zadovoljavajuća. Kao posledica dugogodišnje primene koncepta linearne ekonomije u Srbiji postoji veliki broj divljih deponija, a stopa reciklaže nije adekvatna.

Do sada je izgrađeno 11 sanitarnih deponija. U Srbiji još uvek veliki broj opština/gradova ima sopstvenu deponiju-smetlište. To su nesanitarne deponije za koje je u skladu sa Strategijom o upravljanju otpadom predviđeno saniranje i zatvaranje, jer je kapacitet postojećih deponija-smetlišta u većini opština već popunjen, a većina ne zadovoljava ni minimum tehničkih standarda. Prema podacima dobijenim od 144 jedinice lokalnih samouprava, na njihovoj teritoriji JKP organizovano odlažu otpad na 137 nesanitarnih deponija (smetlišta) lociranih na 111 opština. Podatke o divljim deponijama je dostavilo 131 jedinica lokalnih samouprava i izvestilo postojanje ukupno 2.305 divljih deponija u Republici Srbiji (Agencija za zaštitu životne sredine, 2020).

Prema nekim istraživanjima recikilira se $5-7 \%$ otpada godišnje (OEBS). U vremenu koje se nalazi pred nama, nacionalne ekonomije treba da budu fokusirane na ekonomski rast zajedno sa održivim socijalnim razvojem, uzimajući u obzir zaštitu i unapređenje životne sredine i potrebe pojedinaca (Bogetić et al., 2020).

Prema podacima Republičkog zavoda za statistiku (RZS, 2018), u 2017. godini je izvršena ekstrakcija 107.949 hiljada tona resursa. Najveći iznos ekstrahovanih resursa činila su fosilna goriva - 40.730 hiljada tona, a zatim biomasa - 29.245 hiljada tona. Ukupni troškovi za zaštitu životne sredine u 2017. godini su iznosili 34.400 miliona dinara, što je za $2,7 \%$ manje nego u 2016. godini (RZS, 2018). Učešće investicija u strukturi troškova za zaštitu životne sredine iznosilo je 19,2\%, dok su tekući izdaci iznosili $80,8 \%$ od utrošene sume. Najveće učešće u strukturi investicija za zaštitu životne sredine u 2017. godini odnosilo se na sektor upravljanja otpadom i iznosilo je $37,5 \%$ od ukupnog iznosa investicija. Najveći udeo u strukturi tekućih izdataka za životnu sredinu odnosilo se na upravljanje otpadom i iznosilo je 63,9\%.

\section{SMERNICE ZA UKLJUČIVANJE U PROCESE CIRKULARNE EKONOMIJE / GUIDELINES FOR INCLUSION IN CIRCULAR ECONOMY PROCESSES}

Jedan od zaključaka Agende 21 jeste da je uključivanje organizovane reciklaže u sistem upravljanja otpadom - neophodnost. U tom smislu posmatrano, značaj reciklaže se ogleda u sledećem:

- Stvaraju se uslovi za očuvanje prirodnih resursa

- Vrši se ušteda energije

- Smanjuje se zagađenje životne sredine jer se odlaže manja količina otpada.

Razvoj procesa reciklaže omogućava i:

- Smanjenje cene osnovne sirovine (kao rezultat udaljenosti izvora, ili deficitarnosti sirovine),

- Redukciju troškova koji nastaju zbog uklanjanja otpadaka,

- Smanjenje strateške zavisnosti u proizvodnji - uvoz deficitarnih materijala utiče nepovoljno na privredni razvoj (Bakator et al., 2019).

Da bi reciklaža ostvarila maksimalne efekte po ekonomiju i životnu sredinu, potrebno je da bude institucionalno definisana, što pretpostavlja preciz- 
nu programsku orijentaciju i zakonsku regulativu, kao i moderan pristup upravljanju. Takođe, potrebna je i sveobuhvatnija i kompleksnija akcija na nivou celokupne društvene zajednice, koja podrazumeva edukaciju na svim nivoima, promotivno delovanje u privredi i obrazovnim institucijama, kao i proaktivan pristup svih učesnika u procesu.

Potpuna potencijalna vrednost cirkularne ekonomije prevazilazi samo proces reciklaže. Ova vrednost ugrađena je u ponovnu upotrebu, održavanje, obnavljanje i preradu komponenata i proizvoda, pa je podjednako važno ojačati ove obrnute postavke i mogućnosti (World Economic Forum Ellen MacArthur Foundation and McKinsey \& Company, 2014). Koncept cirkularne ekonomije stvoren je kao odgovor na izazove koji se odnose na iscrpljivanje prirodnih resursa i povećanje obima otpada. Opisuje ekonomski sistem sposoban da se obnovi u životnom ciklusu proizvodnje i potrošnje, u kojem se otpad naknadno koristi ili ponovo koristi kao sirovina u proizvodnom procesu (Rok, Kulik, 2020).

Prema istraživanjima Svetskog ekonomskog foruma (WEF, 2019), mogu se uočiti četiri koraka koji uobličavaju razvoj cirkularne ekonomije. To su: ključna uloga liderstva, uloga i potencijal četvrte industrijske revolucije, uspostavljanje lanca vrednosti cirkularnih materijala i ključna uloga saradnje.

$U$ cilju efikasnije primene cirkularne ekonomije nephodan je razvoj sledećih oblasti (WEF, 2019): a) standardi i propisi, b) promena upravljačkih programa, c) infrastruktura sa omogućenim podacima, d) investicije i f) inovacije i preduzetništvo.

Standardizacija omogućava preduzeću efikasniju proizvodnju, bolju produktivnost i konkurentnost na globalnom tržištu. Preduzeća danas kao imperativ imaju primenu međunarodnih standarda, kao što su: ISO 9001 , ISO 14001, ISO 45000, ISO 31000 i sl. Međutim, postoje i standardi koji pokrivaju oblast cirkularne ekonomije i održivog razvoja, kao što su: Britanski standard za cirkularnu ekonomiju (BS8001) i Evropska direktiva o ekološkom dizajnu, koji uspostavljaju standarde dizajna i komunikacije za proizvode koji su povezanim sa energijom i na taj način omogućavaju energetsku efikasnost. Ovaj standard (BS8001) ima za cilj da pomogne organizacijama i pojedincima u procesu primene cirkularnih i održivih praksi u svom poslovanju, i to kroz unapređenje procesa rada, pružanje više cirkularnih proizvoda i usluga ili redizajniranje celokupnog poslovnog modela i predloga vrednosti.

BS8001 standard je podeljen na dve oblasti: Šta je cirkularna ekonomija i zašto preći na cirkularniji i održiviji način rada? Kako primeniti principe cirkularne ekonomije u organizacionom kontekstu? (BSI Standards Institution, 2017)

U cirkularnoj ekonomiji se preduzetništvo smatra ključnim elementom. Preduzeća koja u svom poslovanju razviju preduzetništvo i inovacije, omogućavaju razvoj cirkularne inovacije. Povezanost između zaštite životne sredine i inovacija datira još od početka 90-ih godina prošlog veka. Zato se danas kao važan segment cirkularne ekonomije postavljaju eko-inovacije. Prema EIO (Eco-Innovation Observatory) (de Jesus, Mendonça, 2018) eko-inovacije (EI) su prepoznate kao poseban put za povećanje efikasnosti i konkurentnosti, istovremeno imajući pozitivne uticaje na životnu sredinu i društvo. Shot i Kanger smatraju da se El može koristiti kao proces transformacije za udaljavanje od statusa kvo, kako bi se stvorio društvenoekonomski sistem zasnovan na konceptu CE. Bag i ostali (Bag and Pretorius, 2020) smatraju da inovativna rešenja mogu pomoći u održivosti CE. Prema Khab i dr. CE je odlična strategija za postizanje korporativne održivosti.

Analiza stavova top menadžera korporacija (Parker, 2020) koje posluju na globalnom tržištu, između ostalog ukazuje na potrebu za sledećim smernicama:

1. razumeti kako radimo i šta vrednujemo,

2. razumevanje tehnologije,

3. kreiranje lokalnog sistema održivosti,

4. unapređenje našeg odnosa sa prirodom,

5. skraćivanje ciklusa inovacija,

6. borba protiv pogrešnih informacija,

7. poslovni lideri treba da se više interesuju za nauku,

8. bolja podrška inovacijma i kreativnosti.

Kako bi preduzeća uspela da posluju na globalnom tržištu, neophodno je da prihvate novi način života i poslovanja, promena u ljudskim potrebama građana i fleksibilnost u svom poslovanju. Preduzeća svoje strategije i vrednosti razvijaju kroz diskusije sa različitim generacijama i kulturama. Informacije koje se dobijaju iz ovih razgovora služe kao korektivni faktor za poslovnu filozofiju preduzeća. U uslovima intezivne primene tehnologija u savremenom poslovanju, preduzeća moraju uskladiti njihovu primenu koje su sve više integrisane u savremeni život građana.

Iskustva iz perioda pandemije COVID-19 pokazao je da su preduzeća čije poslovanje karakteriše visok stepen primene tehnologija lakše prilagodila novonastalim promenama na tržištu. Primena tehnologija u poslovanju je od izuzetnog značaja. Međutim zbog negativnih uticaja na 
društvo i ekonomiju, neophodno je dobra zakonodavna regulativa. Krajnji korisnici i društvo moraju biti zaštićeni od negativnog uticaja novih tehnologija.

Jedna od posledica postpandemije na globalnu ekonomiju je da preduzeća svoj globalni sistem postane lokalniji, održiviji i pravičniji. Naime, preduzeća su fokus poslovanja usmerili na pružanje pogodnosti potrošačima, pandemija je nepovratno preusmerila razgovor na izgradnju otpornosti zajednice. Pitanje poverenja od strane potrošača i ostalih zainteresovanih strana je od izuzetne važnosti za poziciju lokalnih lanaca snabdevanja. Vlade sada aktivno sarađuju sa zainteresovanim stranama u čitavom poljoprivrednom lancu snabdevanja kako bi promovisale i investirale u inovacije povezane sa unutrašnjom poljoprivredom, preciznom poljoprivredom, sigurnošću i očuvanjem hrane, smanjenjem otpada $i$ alternativnim proteinima. Udruženja potrošača imaju veliki uticaj na unapređenje lance snabdevanja i to kroz informisanje preduzeća o svojim navikama i na taj način doprinose kreiranju inovacija u lancu snabdevanja. Kao rezulat ovih aktivnosti imamo zdraviju zajednicu i planetu.

Jedna od posledica pandemije COVID-19 jeste što je pokazala neadekvatan odnos preduzeća prema prirodi, što je za rezultat imala i krhkost postojećeg pristupa zdravstvenog sistema zaštite. Ljudi su danas u cilju svoje zdravstene i mentalne zaštite okrenuli prirodi i zdravom načinu života. Takođe, potrebno je da preduzeća i ljudi sve više razumeju i poštuju prirodu i njene prednosti koja nam pruža.

Preduzeća sa svojim kapacitetima moraju da reaguju na promene na tržištu na taj način što će ponuditi novu ideju ili inovaciju koja sa jedne strane odgovora potrebama lokalnog tržišta, a sa druge strane je brža i efikasnija od prethodno urađenih inovacija.

Preduzećima je danas znanje koje se odlikuje istinitim podacima od izuzetnog značaja. Poslovna praksa je pokazala da u ovom vremenu koje karakteriše ekspanzija informacija dosta lako širiti dezinformacije koje mogu negativno uticati na motivaciju zaposlenih i krajnjih korisnika.

Savremeni lideri posebnu pažnju posvećuju javnom zdravlju i bezbednosti i u tu svrhu su radi da se konsultuju sa naučnim stručnjacima ukoliko to prevazilazi njihovo polje obrazovanja. Novi lideri imaju svest da se moraju ojačati javne institucije u cilju smanjenje krize i po cenu umanjenja njihovog autoriteta. Da bi se promene dogodile (Parker, 2020), moramo stvoriti programe obuke i razvoja liderstva za javni i privatni sektor koji su snažnije usmereni na (a) potrebe sledbenika; (b) jačanje kompetencija u domenu javnog zdravlja i bezbednosti (uključujući obuku o prepoznavanju problema mentalnog zdravlja među sledbenicima); (c) prednosti deljenja vođstva sa stručnjacima.

Preduzeća u svom poslovanju sve više primenjuju nove tehnologije, i idu ka procesu digitalizacije. Međutim, preduslov za primenu novih tehnologija i digitalizacije jeste da je preduzeće, kao i same nacionalne ekonomije okrenute ka razvoju inovacija i kreativnosti. Kao rezultat ovih aktivnosti imamo stimulaciju inovatora, preduzetnike i novonastala preduzeća koja donose raznolikost i kreativnost tehnološkim inovacijama.

\section{ZAKLJUČAK / CONCLUSION}

Cirkularna ekonomija predstavlja novi poslovni model u čijem fokusu je ponovna upotreba materijala u procesu reciklaže, odnosno ponovno preosmišljavanje proizvoda za novu upotrebu. Novi proizvodi koji su nastali od recikliranih materijala prilikom kreiranja moraju imati sledeće karakteristike: izdržljivi, sposobni za nadogradnju, da imaju mogućnost za ponovnu upotrebu. $U$ tu svrhu preduzeća u svojim proizvodnim procesima moraju da razvijaju inovacije.

Ukoliko preduzeća žele da aktivno primenjuju osnove koncepta održivog razvoja, ona moraju da vode računa o odgovornoj potrošnji i proizvodnji. Tu se najviše misli na smanjenje zagađenja životne sredine u odnosu na ekonomski razvoj, održivu potrošnju energije i upravljanje otpadom.

Primenom koncepta cirkularne ekonomije, privreda Srbije bi dobila šansu za razvoj, a društvo i građani bi dobili unapređenje zaštite životne sredine, po osnovu šire primene smanjivanja otpada, kao i otvaranje novih radnih mesta koja bi se kreirala u sektoru prerade otpada.

Standardizacija i preduzetništvo predstavljaju najznačajnije oblasti koje mogu pomoći organizacijama u daljem razvoju i u unapređenju cirkularne ekonomije. Standardizacija kroz primenu međunarodnih upravljačkih standarda (ISO 9001, ISO 14001, 9001, ISO 45000, ISO 31000), kao i određenih nacionalnih standarda BS8001 omogućava efikasnost poslovnih procesa u organizaciji i bolju primenu CE. Preduzetništvo je od ključnog značaja za CE, jer se kroz inovacije kreiraju nova rešenja u oblasti eko dizajna i ponovne upotrebe sirovina. 


\section{LITERATURA / REFERENCES}

[1] Agencija za zaštitu životne sredine (2020). Upravljanje otpadom u Republici Srbiji u periodu 2011-2019. Available at:

http://www.sepa.gov.rs/index.php?menu=5000\&i $\mathrm{d}=13 \&$ akcija=showExternal

[2] Bag, S., \& Pretorius, J. H. C. (2020). Relationships between industry 4.0 , sustainable manufacturing and circular economy: proposal of a research framework. International Journal of Organizational Analysis, (ahead-of-print), https://doi.org/10.1108/IJOA-04-2020-2120

[3] Bakator, M., Đorđević, Lj., \& Đorđević, D., (2019). Circular economy and the domestic economy challenges and limitations. IX International conference Industrial engineering and environmetal protection 2019 (IZZS 2019), Zrenjanin, Serbia, TF Mihajlo Pupin Zrenjanin, pp. 527-532.

[4] Bogetić, S., Đorđević, D., Đorđević, Lj., \& Bakator, M., (2020). Analiza aspekata unapređenja životne sredine u procesu razvoja konkurentnosti. Ecologica, 27(97), 123-128.

[5] BSI Standards Institution (2017). BS 8001: 2017 - Framework for implementing the principles of the circular economy in organizations - Guide. BSI Standards Institution.

[6] de Jesus, A., \& Mendonça, S. (2018). Lost in Transition? Drivers and Barriers in the Ecoinnovation Road to the Circular Economy. Ecological Economics, 145, 75-89.

[7] Đorđević, Lj., \& Bijelović, S., (2008). Unapređenje procesa reciklaže u domaćoj privredi, Međunarodna konferencija o upravljanju zaštitom životne sredine u elektroprivredi "ELECTRA V", EPS, EPCG i EPRS i Forum za kvalitet Beograd, Divčibare.

[8] Ellen Macarthur foundation (2019). Completing the picture: how the circular economy tackles climate change. Available at:

www.ellenmacarthurfoundation.org/publications

[9] Ellen MacArthur Foundation, McKinsey \& Comp., (2014). Towards the Circular Economy: Accelerating the scale-up across global supply chains. Available at: www.weforum.org

[10] European Commission Directorate-General for Research and Innovation (2019). Accelerating the transition to the circular economy - Improving access to finance for circular economy projects. Luxembourg: Publications Office of the European Union.

[11] Europska komisija (2020). Akcijski plan za kružno gospodarstvo: Za čišću i konkurentniju Europu. Europska komisija, Luxembourg: Ured za publikacije Europske unije.
[12] Europska komisija EK (2015). Komunikacija komisije europskom parlamentu, vijeću, europskom gospodarskom i socijalnom odboru i odboru regija: Zatvaranje kruga - akcijski plan EU-a za kružno gospodarstvo. Europska komisija (EK), COM (2015), 614, Bruxelles.

[13] Eurostat (2018). Sustainable development in the European Union - Overview of progress towards the SDGs in an EU context. Available at: https://ec.europa.eu/eurostat/web/productsstatistical-books/-/KS-01-18-656

[14] Ilić-Kosanović, T., Tomašević, V., \& Tomić, S. (2019). Engineering a conceptual circular economy model for creating jobs in the Republic of Serbia. Ecologica, 26 (95), 153-158.

[15] Lopes de Sousa Jabbour, A.B. (2019). Going in circles: new business models for efficiency and value. Journal of Business Strategy, 40 (4), 3643. https://doi.org/10.1108/JBS-05-2018-0092

[16] Maldonado-Guzmán, G., Garza-Reyes, J.A., \& Pinzón-Castro, Y. (2020). Eco-innovation and the circular economy in the automotive industry. Benchmarking: An International Journal, (ahead-ofprint). https://doi.org/10.1108/BIJ-06-2020-0317

[17] OEBS (2017). Cirkularna ekonomija kao šansa za razvoj Srbije. OEBS Misija u Srbiji, Beograd.

[18] Parker, C. (2020). 20 views on how to rebuild better after the pandemic. Available at https:// www.weforum.org/agenda/2020/11/whats-thebiggest-opportunity-for-change-after-the-pandemic/

[19] Rok, B., \& Kulik, M. (2020). Circular start-up development: the case of positive impact entrepreneurship in Poland. Corporate Governance, (ahead-of-print), https://doi.org/10.1108/CG-012020-0043

[20] RZS (2018). Indeksi materijalnih tokova u 2017. Available at: https://www.stat.gov.rs/srlatn/vesti/20191205-indikatori-materijalnihtokova-2018/

[21] The Platform for Accelerating the Circular Economy (PACE) (2020). The circularity Gap report 2020. Available at: https://circularity-gap.world/

[22] Troškovi za zaštitu životne sredine u 2017. (2018). RZS, Beograd.

[23] WEF (2019). 4 Key steps towards a circular economy. Available at:

https://www.weforum.org/agenda/2019/02/4-keysteps-towards-a-circular-economy/

[24] World Economic Forum (2019). Harnessing the Fourth Industrial Revolution for the Circular Economy: Consumer Electronics and Plastics Packaging. Available at: www.weforum.org. 